\title{
Motivation and Job Satisfaction in Hospital Employees of Sanandaj
}

Sohrabi. F1
${ }^{*}$ Ramezani. G 2
Pourbairamian. G2
Norozi. A ${ }^{2}$
1- Ph.D. Student of Clinical
Psychology, Clinical
Psychology Department,
Faculty of Medicine, Shahid
Beheshti University of Medical
Sciences, Tehran, Iran.
2- (*Corresponding Author)
Ph.D. Student in Medical
Education, Center for
Educational Research
in Medical Sciences
(CERMS), Medical Education
Department, Faculty of
Medicine, Iran University of
Medical Sciences (IUMS),
Tehran, Iran.
Email: ramazanighobad@
gmail.com

\begin{abstract}
Introduction: The efficacy and success of an organization depend on its employees' performance and satisfaction. On the other hand, motivating employees to improve their work quality and increase their productivity are essential principles of one organization's staff management.
\end{abstract}

Objective: This research aimed to study the motivation and job satisfaction and their relations in hospital staff in Sanandaj Kurdistan province.

Materials and Methods: As a cross-sectional study, 175 hospital employees in Sanandaj were selected through a simple random sampling method. Scales were Verve's Bayfield test for measuring personal satisfaction, and a researcher-made questionnaire according to the Herzberg theory for measuring job motivation which its initial Cronbach was in an acceptable range (0.87). Data were analyzed through SPSS version 22

Results: The overall mean of job satisfaction for nurses was 3.12, for office personnel 3.09 , and personnel in the service category was 2.75 , these means are below the normal mean. Job satisfaction didn't show meaningful differences between groups but it has a positive correlation with motivation $(\mathrm{r}=0.572)$. Among motivational factors, the sense of responsibility with 3.9 score, development and progress 3.18 , and health-related factors such as good income 3.9, and good relationship with others 3.81 , were prioritized in the second level of determinative factors.

Discussion and Conclusion: According to the study findings, and the fact that motivation and job satisfaction are highly influential factors in increasing the productivity of an organization, hospital management should pay special attention to motivating employees and improving approaches to increase satisfaction among their staff.

Keywords: Hospital, Motivation, Personnel, Personal Satisfaction, Personnel Management. 


\section{بررسى ميزان انكيزش و رضايت شغلى كار كنان بيمار ستانهاى سندج}

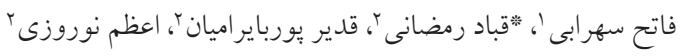

جكيده

مقدمه: اثربخشى و موفقيت يك سازمان به عملكرد كاركنان و ميزان رضايت آنها بستگى دارد. از سوى ديخر ايجاد انكيزه در كاركنان براى بالا بردن كيفيت كار و بهرهورى هر جه بيشتر در آنان از اصول ضرورى مديريت نيروى انسانى يك سازمان مىباشد. هدف: هدف مطالعه حاضر بررسى ميزان انخيزش و رضايت شغلى و همجنين ارتباط متقابل آنها در يرسنل درمانى بيمارستانهاى شهر سنندج بود.

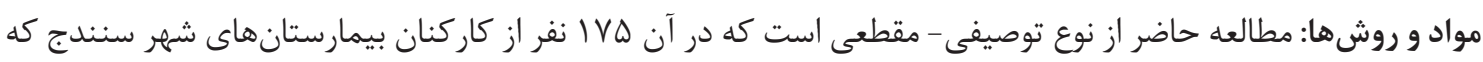

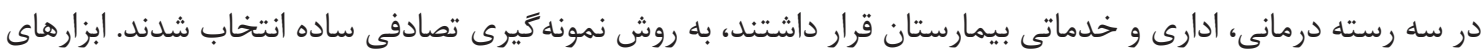

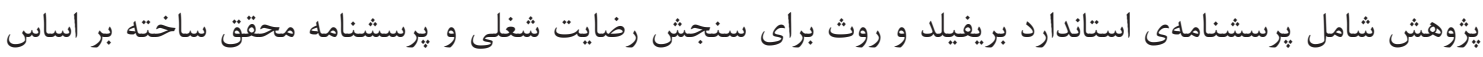

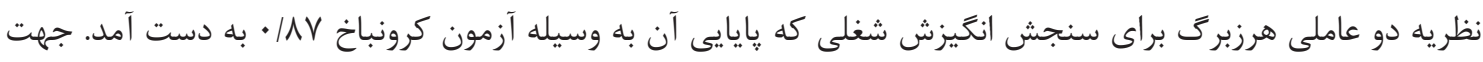
تحليل دادها از نرمافزار SPSS نسخة r ب استفاده شد.

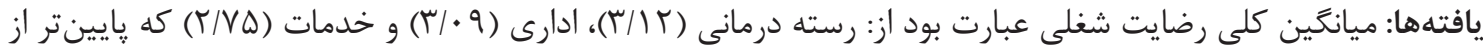

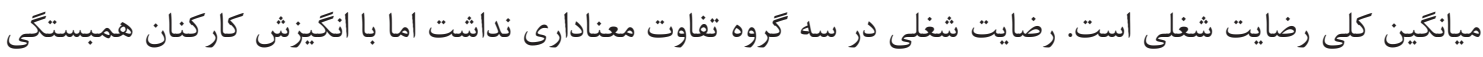

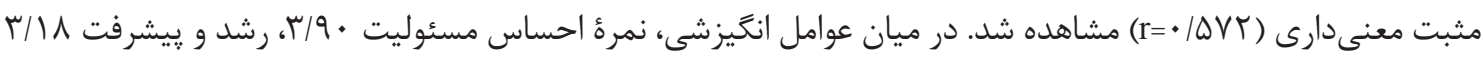

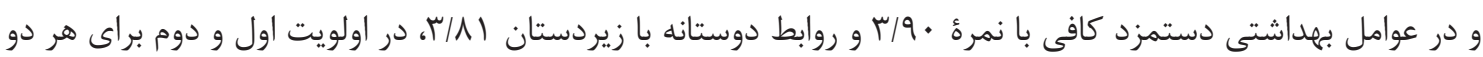
متغير بودند. بحث و نتيجه كيرى: با توجه به يافتههاى مطالعه و لزوم توجه به اين نكته كه انكيزش و رضايت شغلى كاركنان از عوامل

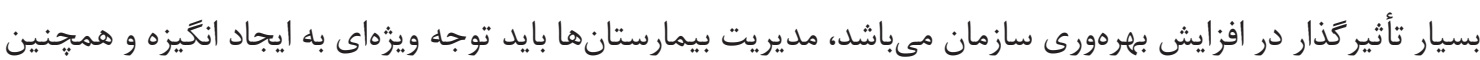
اتخاذ رويكردهايى در ارتباط با افزايش رضايتمندى در بين كاركنان خود داشته باشند. كلمات كليدى: انكَيزش، بيمارستان، رضايت شغلى، كار كنان، مديريت بيمارستان.

\begin{tabular}{|c|c|c|}
\hline 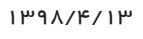 & 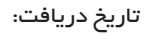 & 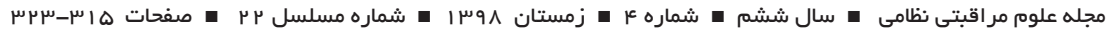 \\
\hline १ & تاريخ يذيرش: & \\
\hline 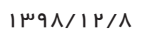 & تاريخ انتشار: ت & \\
\hline
\end{tabular}

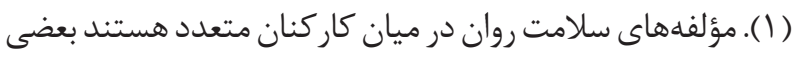

مقدمه از جمله آنهايى كه بيشتر مورد توجه قرار كرفتهاند مى توان به به مانه از مشخصات يك سازمان سالم آن است كه سلامت جسمانى

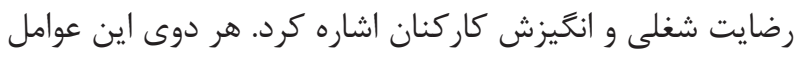
و روانى كاركنان رضايت شغلى آنان به همان اندازه توليد و ورهان

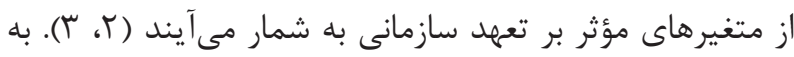

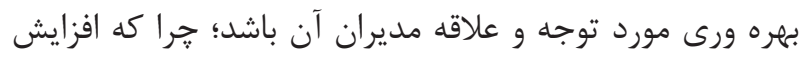
همين دليل است كه همواره از موضوعات اساسى و مورد توجه بهرهورى و كارايى كاركنان موجب ارتقاء كل سازمان خواهد شد 
برانگيختكى و هدايت و تداوم اعمال ارادى فرد مىشود، به عبارت

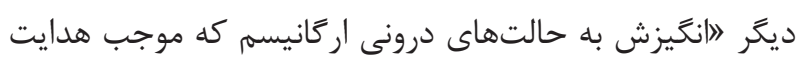

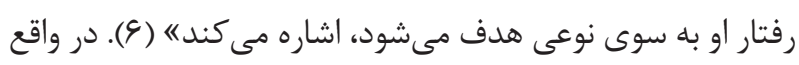

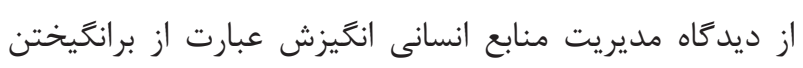

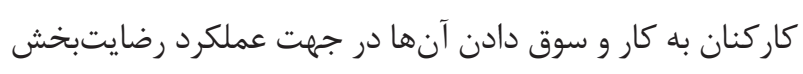

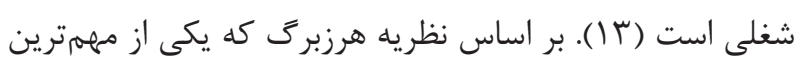

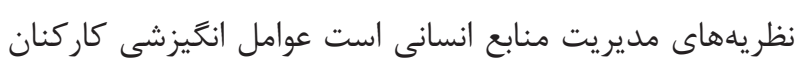

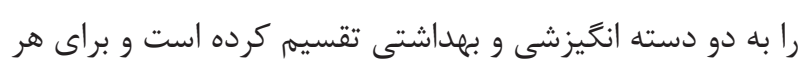

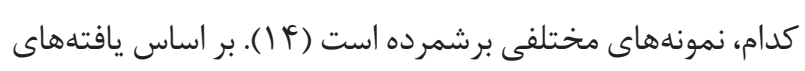

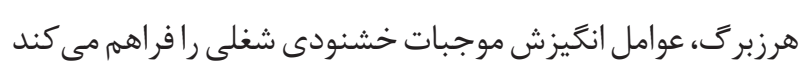

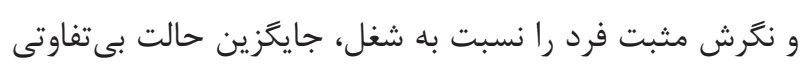

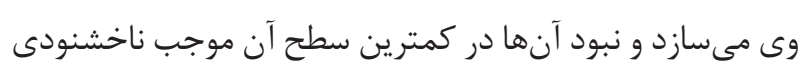

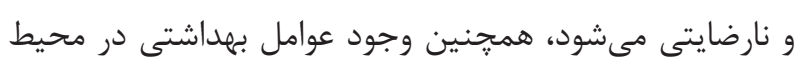
كار موجب احساس رضايتمندى در سازمانها شده و نبود آنها

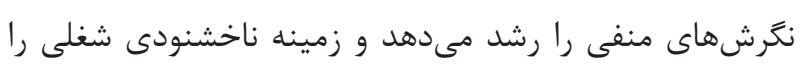

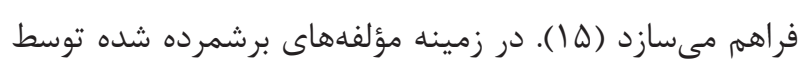

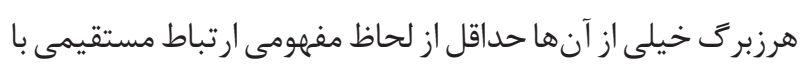
رضايت شغلى دارند. براى مثال در مطالعهاى بهبود شرايط كارى و و

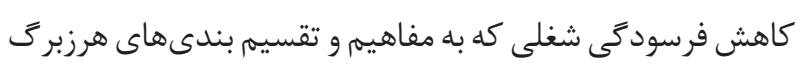

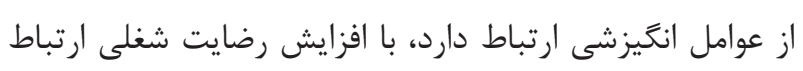

$$
\text { مثبتى نشان داد (•) (1). }
$$

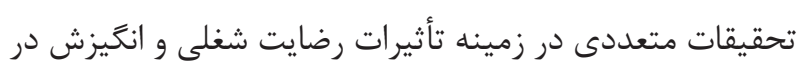
محيطهاى بيمارستانى و درمانى انجام شده است. در مطالعهاى دئي

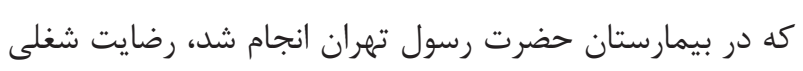

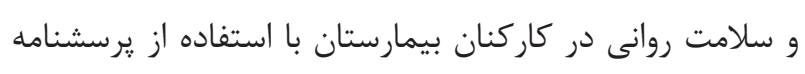

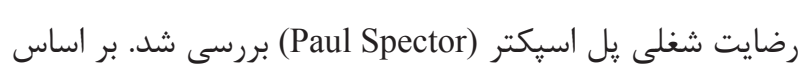

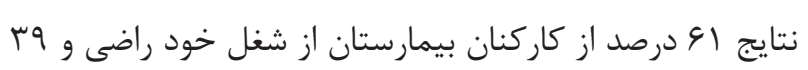

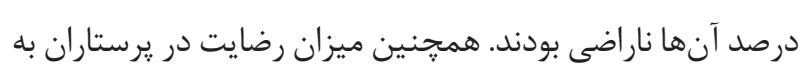

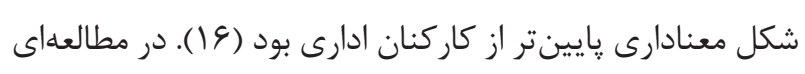
ديخر كه با هدف بررسى ميزان رضايت شغلى يرستاران بخشهادي

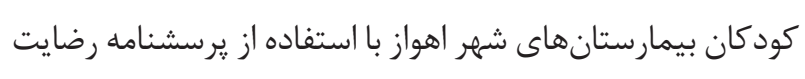
شغلى (Minnesota Job Satisfaction Questionnaire- MCQ) انجام شد. نتايج يزوهش نشان داد كه ميزان رضايت شغلى صها

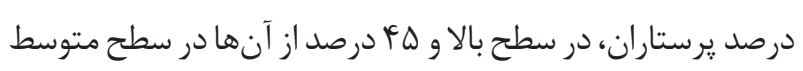

در مديريت نيروى انسانى به شمار آمدهاند و فقدان توجه به آنها

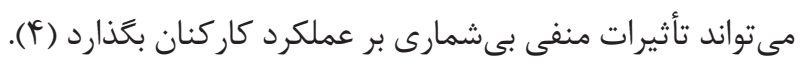

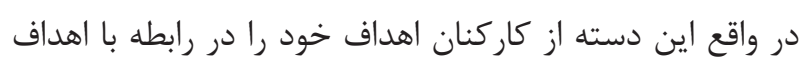

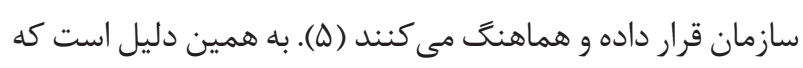
در سطوح مختلف فرايندى و محتوايى مورد بررسى قرار كرفتهاند

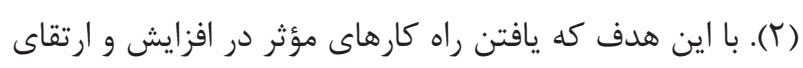

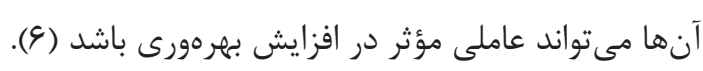
رضايت شغلى به مجموع تمايلات يا احساسات مثبت كه افراد نسبت به شغل خود دارند اطلاق مى كَردد (V) كه متأثر از عوامل متعددى مانند حقوق و دستمزد، ارتباطات، سياستها، رويهها،

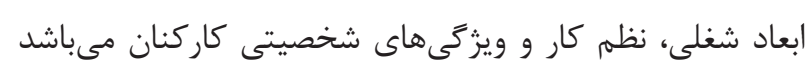
(1). به طور كلى رايجترين و كاربردى ترين تئورى مورد استناد در بررسى رضايت شغلى، تئورى هرزبرى (Herzberg Theory)

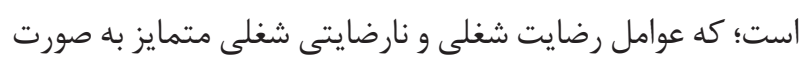
جدا از يكديكر تميز داده و مشخص نموده است (َا). از اين

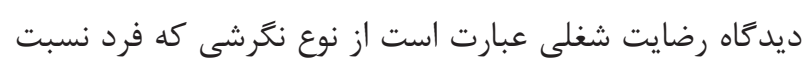

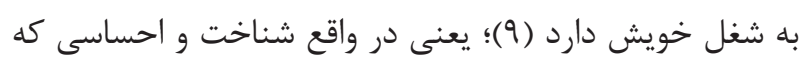

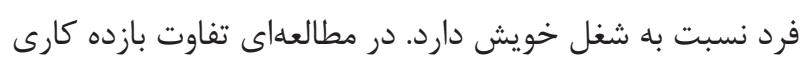

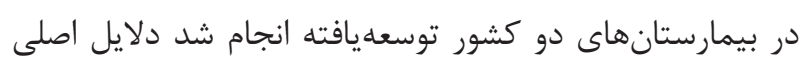
اين تفاوت را به مسائل مربوط به رضايت شغلى مرتبط دانستند

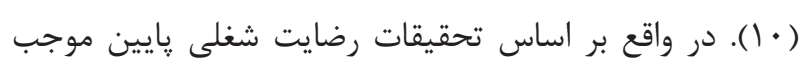

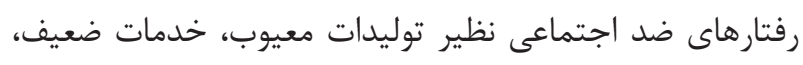
توليد و وخش شايعه مخرب، غيبت، جابجايى و ترك كار كاركنان مى كردد (9). بعضى از نويسند

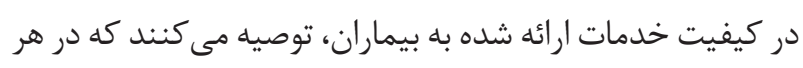
شش سال يكبار به طور منسجمى مورد بررسى قرار گيرد (11).

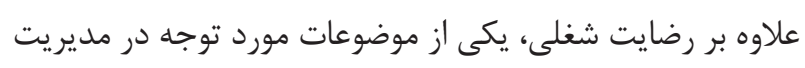

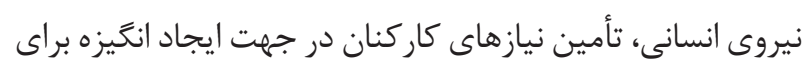

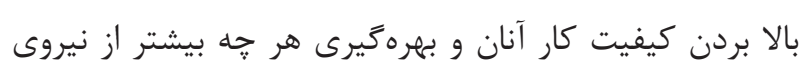

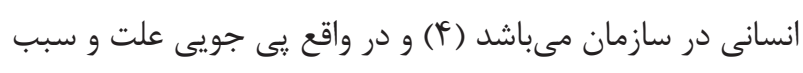

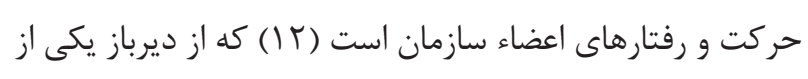

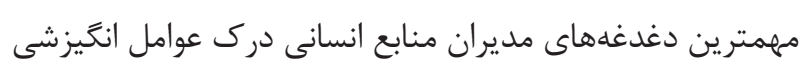

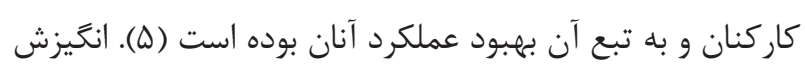

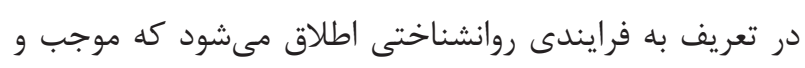


باعث كاهش روحيه كاركنان، تشويش، كم كارى، غيبت، استعفا،

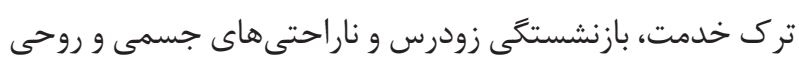

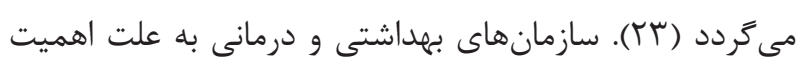

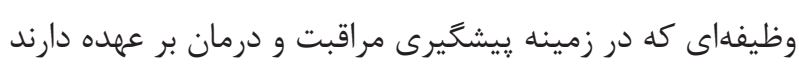

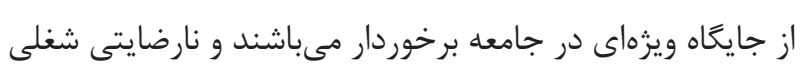

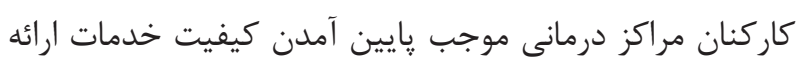

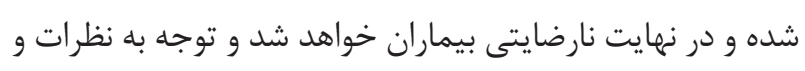

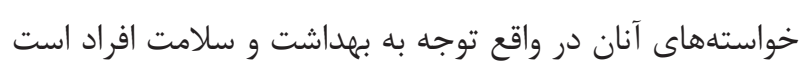

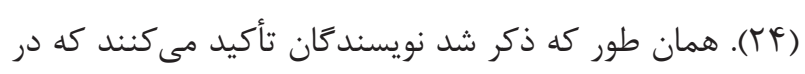

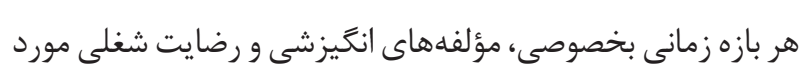

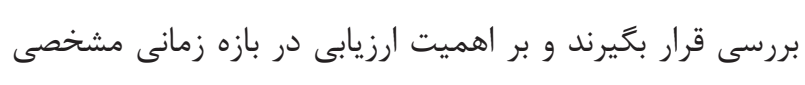

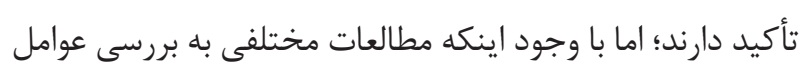

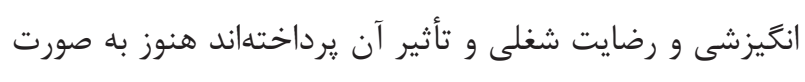

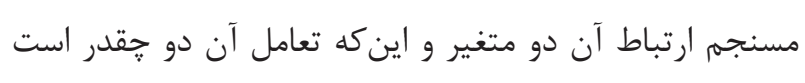

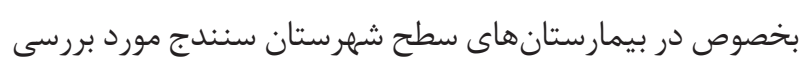

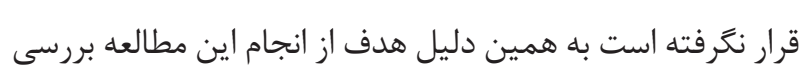
ميزان انكيزش و رضايت شغلى و ارتباط اين دو در بين يرسنل درمانى بيمارستانهاى شهر سنندج بود رضئ

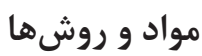

اين يزوهش يك مطالعه توصيفى و از نوع مقطعى بود كه در سال

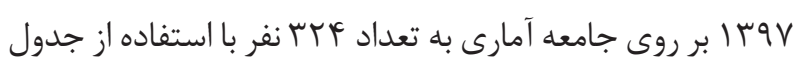

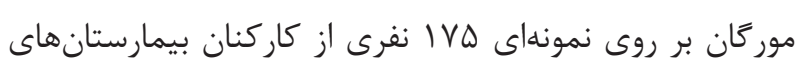

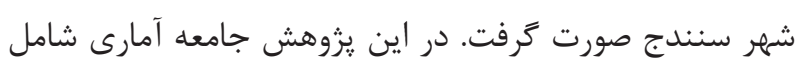

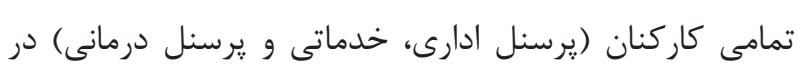
بيمارستانهاى بعثت، توحيد، قدس و تأمين اجتماعى شهر سنندج إندان

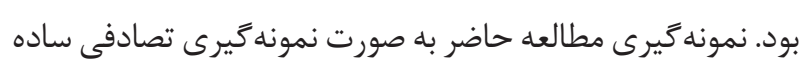
انجام شد. به منظور جمع آورى اطاعات از يرسشنامه استاندارد

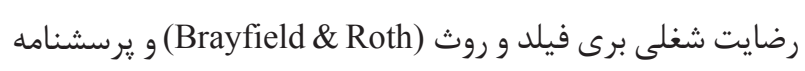

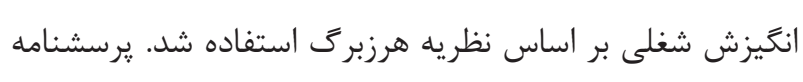

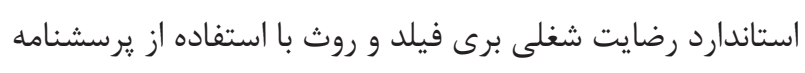
استاندارد شده رضايت شغلى برى فيلد و روث كه داراى 19 سؤال

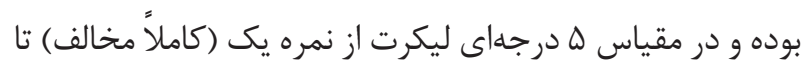

قرار دارد. متوسط رضايت شغلى برستاران VY/\& د درصد به دست آمد (IV) (IV نتايج بررسى رضايت شغلى كار كنان بهداشتى در استان جهارمحال و بختيارى با استفاده از يرسشنامه JDI (يرسشنامه

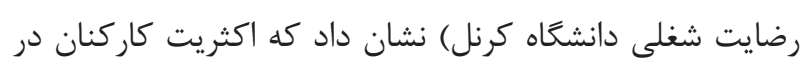

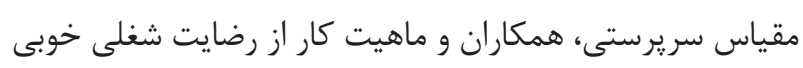

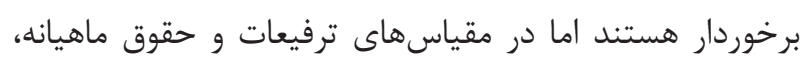

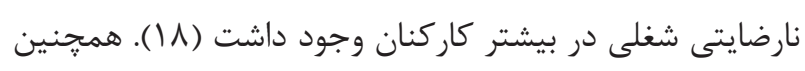

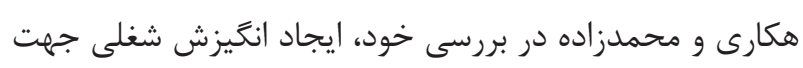

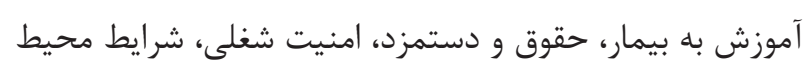

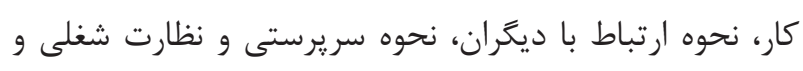

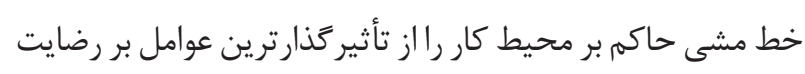

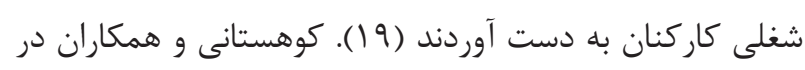

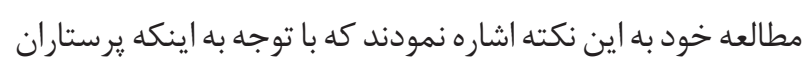

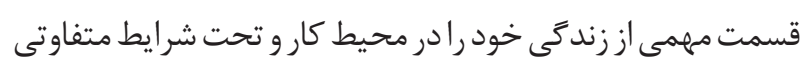

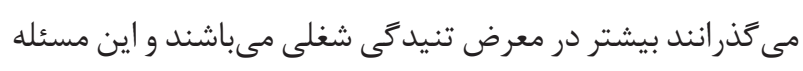

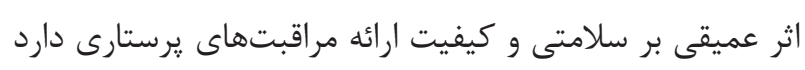

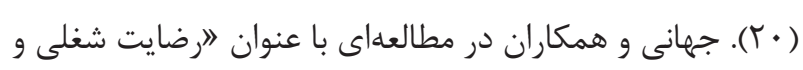

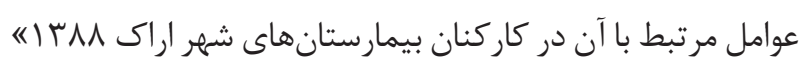
نتيجه كرفتند كه رضايت شغلى اكثر كاركنان از شرايط محل كار

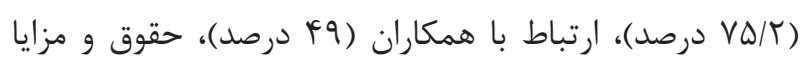

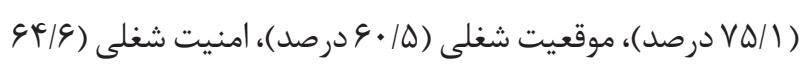

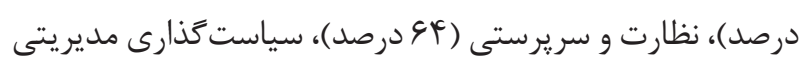

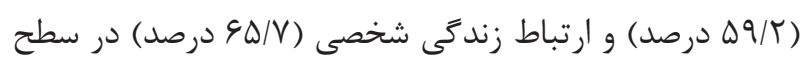

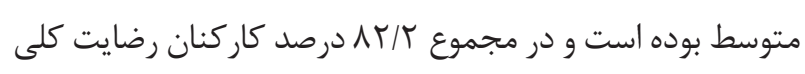

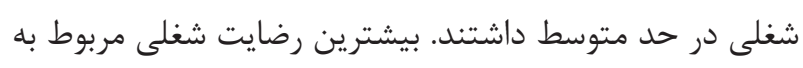

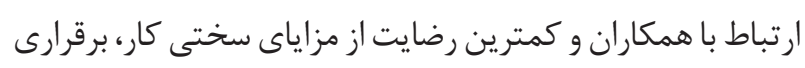
عدل و انصاف و عدم وجود تبعيض و امكانات رفاهى بود. آزمون

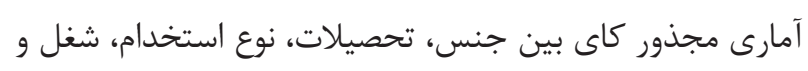
شيفت كارى ارتباط معنى دارى نشان داد ( (Y).

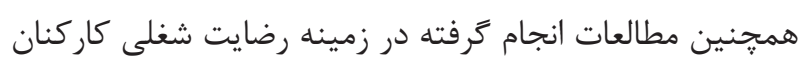

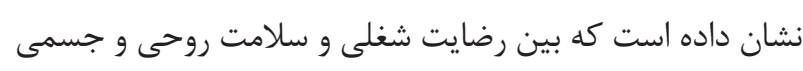

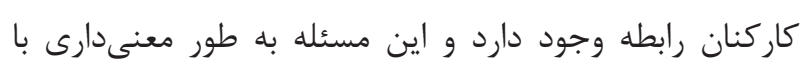
مشكلات روحى و روانى، خستخى مفرط، اعتماد به نفس، افسردگى إنى

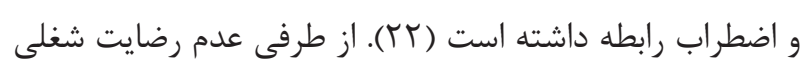


آمده از اين قسمت نيز برابر با \ه| • بيان شد. پايايى يرسشنامه

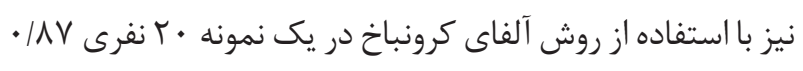

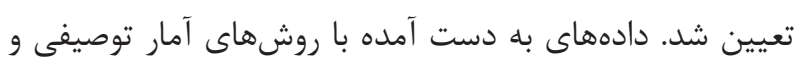

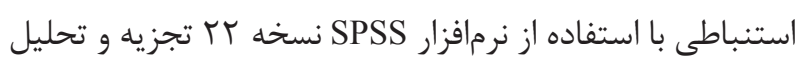
شدند. ملاحظات اخلاقى و معيارهاى ورود به مطالعه: به منظور

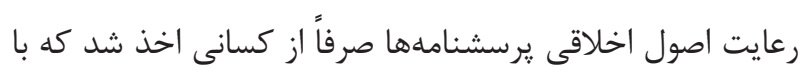
رضايت آكاهانه اقدام به همكارى در يزوهش و و تكميل اطلاعات برسات لازم را داشتند. همجنين اطلاعات اخذ شده كاملاً محرمانه و ورئه

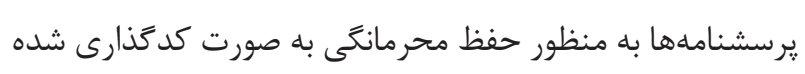
تكميل شدند. علاوه بر اين، هدف از انجام مطالعه براى افراد نمونه

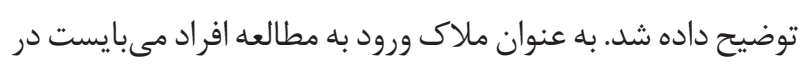

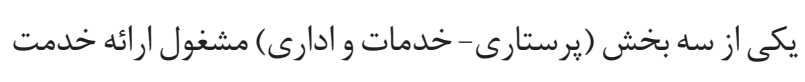

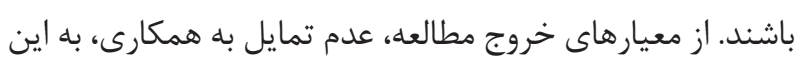
صورت كه افراد در صورت منصرف شدن از تكميل اطلاعات لازم

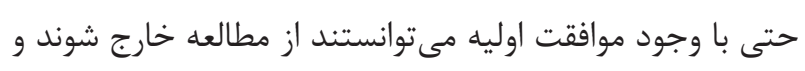
اطلاعات تكميل شدهشان نيز از فرايند تحليل كنار حذاشته مى شعد.

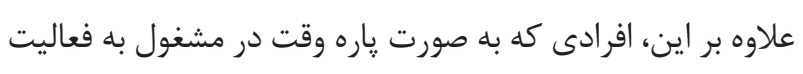

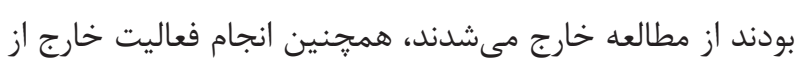

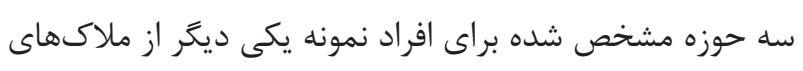

$$
\text { خروج محسوب مىشد. }
$$

\section{بافتهها}

اطلاعات جمعيت شناختى مربوط به كروه نمونه از قبيل جنسيت، سن، تحصيلات، رسته شغلى، سابقه خدمت و وضعيت تأهل در جريت

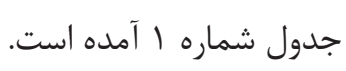

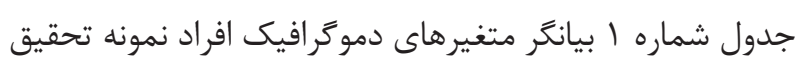

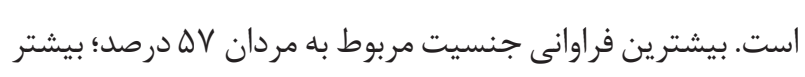

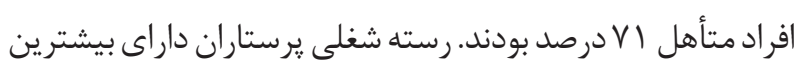

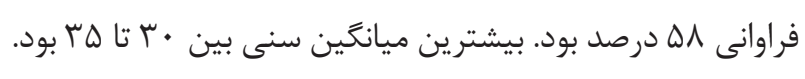

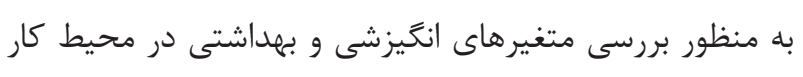

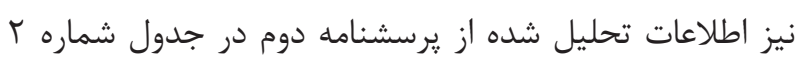
نمايان است. دادههاى حاصل از جدول بالا بيان خر اين است كه در ميان عوامل

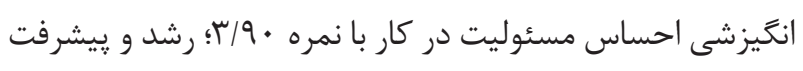

رضايت شغلى كاركنان استفاده شد. برى فيلد و روث پايايى اين

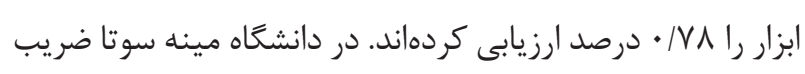

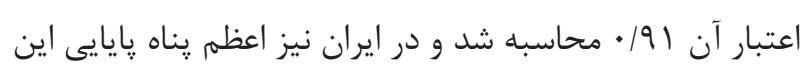

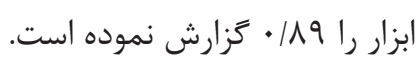

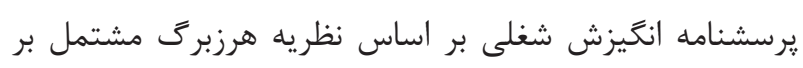

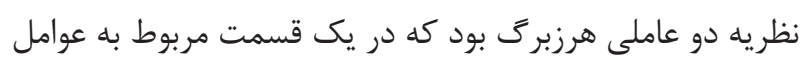

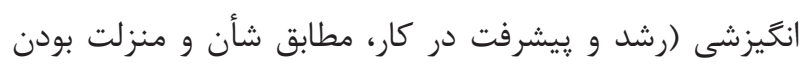

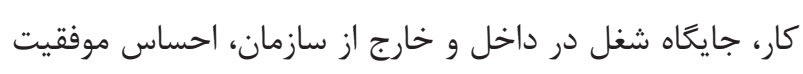

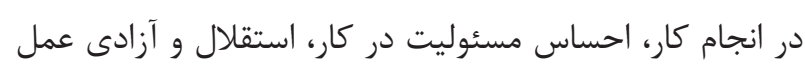

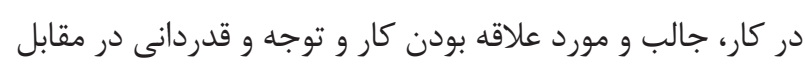
انجام كار بود كه وجود هر يك از عوامل فوق راد در ايجاد انغَيزه براى عملكرد بهتر هر يك از كاركنان مىسنجيد) و در قسمت وند

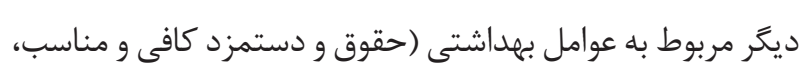

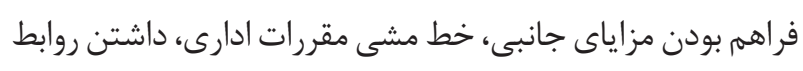

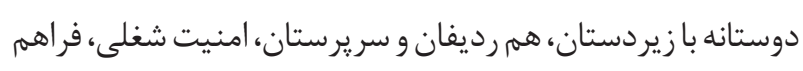

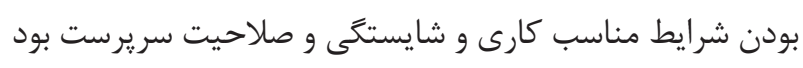
كه كمبود هر يك از عوامل فوق را در ايجاد نارضايتى كاركنان

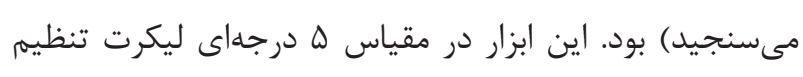

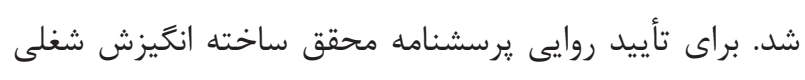

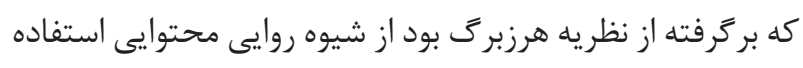

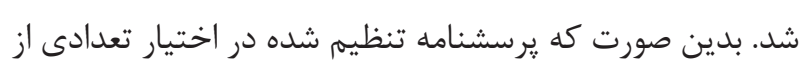
صاحبنظران قرار كرفت و روايى محتوايى آن تأييد كرديد. جهت بررسى شاخص روايى محتوا از روش والتز و باسل \&altz \& استفاده شد (Y Bausell)

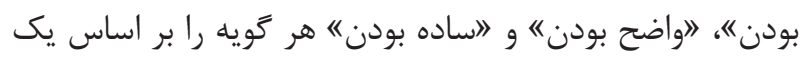

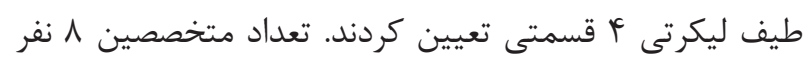

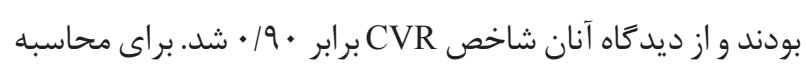
CVI

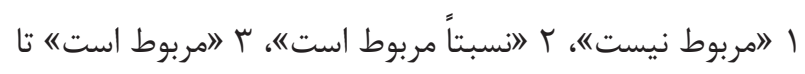

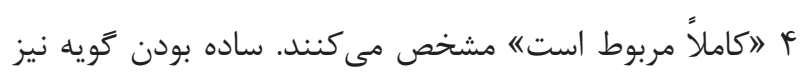

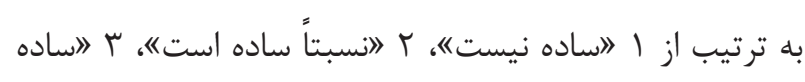

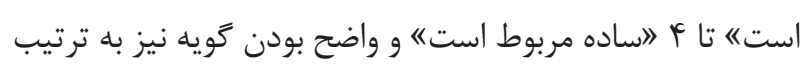

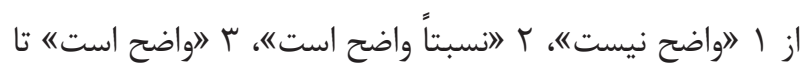

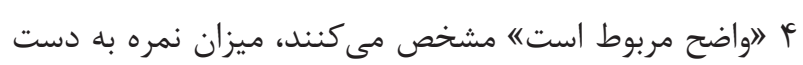


در كار با نمره 1// / آ؛ و در ميان عوامل بهداشتى حقوق و دستمزد

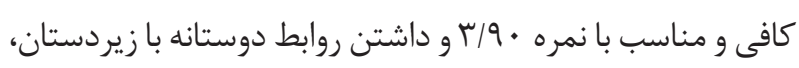

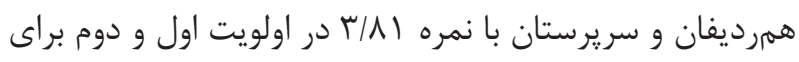
هر دو متغير هستند. نمره ميانكين كلى رضايت شغلى عبارت بود از رسته يرستاران (Y/T)

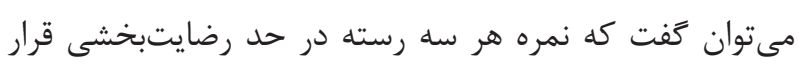

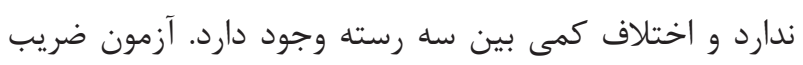
همبستخى بيرسون براى بررسى دو رابطه بين متغيرها صورت

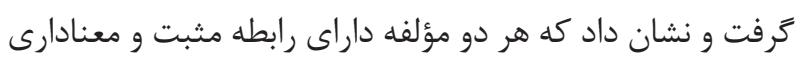

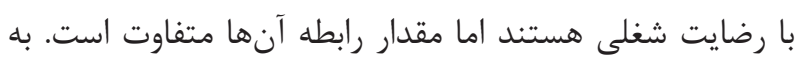

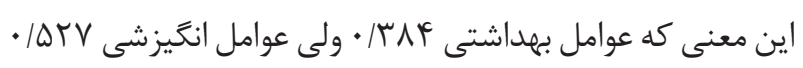

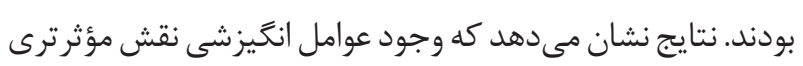
در رضايت شغلى آنان داشته است و عدم وجود اين عوامل مى تواند به نارضايتى شغلى منجر كردد.

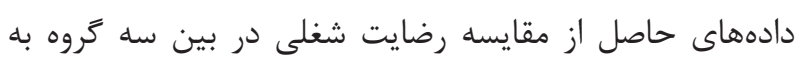

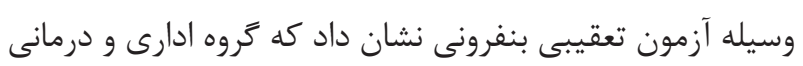

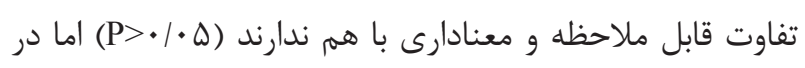

جدول (- متغيرهاى جمعيت شناختى افراد گروه نمونه

\begin{tabular}{|c|c|c|c|}
\hline درصد فراوانى & فراوانى & مؤلفهها & متغير \\
\hline$\cdot / \Delta V$ & $1 \cdots$ & 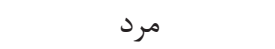 & \multirow{2}{*}{ جنسيت } \\
\hline ש & $V \Delta$ & 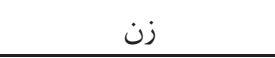 & \\
\hline$\cdot / T q$ & iv & مجرد & \multirow{3}{*}{ وضعيت تأهل } \\
\hline$\cdot|V|$ & ITA & متأهل & \\
\hline 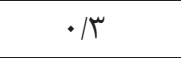 & 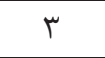 & بيوه/مطلقه & \\
\hline$\cdot \mid \Delta \Lambda$ & $1 \cdot r$ & يرستار & \multirow{3}{*}{ رسته شغلى } \\
\hline$\cdot / 4 \Lambda$ & $i \wedge$ & ادارى & \\
\hline.$/ 10$ & $r \Delta$ & خدماتى & \\
\hline.$/ 4 t$ & rq & •r.r. & \multirow{4}{*}{ سن } \\
\hline$\cdot / \uparrow \wedge$ & M & • & \\
\hline$\cdot|r|$ & $r \Delta$ & Dال- & \\
\hline$\cdot 1 \cdot 9$ & If & لها & \\
\hline$\cdot / r q$ & 99 & دييلم / فوقديِلم & \multirow{3}{*}{ تحصيلات } \\
\hline$\cdot \mid \Delta F$ & 97 & ليسانس / فوق ليسانس & \\
\hline$\cdot / \cdot V$ & ir & دكترى & \\
\hline$\cdot|r|$ & ऍ人 & ف- • 1 سال & \multirow{4}{*}{ سابقه خدمت } \\
\hline$\cdot /$ r & $9 \Delta$ & . & \\
\hline$\cdot / T F$ & er & ها - • • سال & \\
\hline$\cdot / 11$ & $r \cdot$ & بالاى •r سال & \\
\hline
\end{tabular}

جدول r - بررسى وضعيت انگيزشى و بهداشتى محيط كار

\begin{tabular}{|c|c|c|}
\hline 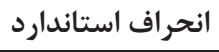 & ميانكَين & متغير انكَيزشى // بهداشتى" \\
\hline 1/9Tr & $r / \Lambda$ & |رشد و ييشرفت در كار || \\
\hline $1 / \mathrm{VI}$ & $r / 9$. & حقوق و دستمزد كافى و مناسب* \\
\hline$r / r q$ & T/lF & مطابق شأن و منزلت بودن كار || \\
\hline$r / l \cdot$ & $r / 9 V$ & فراهم بودن مزاياى جانبى* \\
\hline T/19 & r & جايگاه شغل در داخل و خارج از سازمان/| \\
\hline $1 / \mu F$ & $r / 11$ & |حساس موفقيت در انجام كار || \\
\hline r/A & $r / 94$ & خط مشى مقررات ادارى* \\
\hline $1 / 1 \mathrm{~V}$ & r/gY & |حساس مسئوليت در كار || \\
\hline r/99 & $\mathrm{r} / \Lambda 1$ & داشتن روابط دوستانه با زيردستان، همرديفان و سريرستان* \\
\hline$r / 9 \cdot$ & r & استقلال و آزادى عمل در كار || \\
\hline r/^ & r/ & 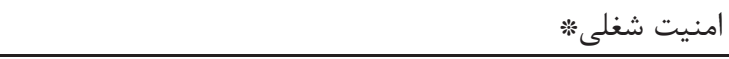 \\
\hline$r / l f$ & $r / \cdot r$ & جالب و مورد علاقه بودن كار || \\
\hline $1 / r 1$ & $r / 19$ & فراهم بودن شرايط مناسب كارى* \\
\hline$r / \Delta \Delta$ & r/A & "توجه و قدردانى در مقابل انجام كار || \\
\hline$r / 94$ & r & شايستگى و صلاحيت سريرست* \\
\hline
\end{tabular}


جدول ب - بررسى ميزان رضايت شغلى با دو مؤلفه انگيزش و بهداشت

\begin{tabular}{|c|c|c|c|c|}
\hline \multicolumn{2}{|c|}{ بهداشت } & \multicolumn{2}{|c|}{ انغيزش } & \multirow{2}{*}{ متغير } \\
\hline ضريب همبستكى & Sig & ضريب همبستكى & Sig & \\
\hline$\cdot / r \wedge F$ & $\cdot 1 \cdots$ & $\cdot / D T V$ & $\cdot 1 \cdots$ & رضايت شغلى \\
\hline
\end{tabular}

جدول F - نتايج تحليل واريانس يك طرفه براى تفاوت بين زير تروههاى نمونه با ميزان رضايت شغلى كروه

\begin{tabular}{|c|c|c|c|c|c|}
\hline سطح معنادارى & سطح آماره & ميانغين مجذورات & مجموع مجذورات & منابع تغيير & \\
\hline \multirow{3}{*}{$\cdot 1 \cdot \cdot 1$} & \multirow{3}{*}{$r / \Lambda \Delta H$} & $\vee q / 4 q$ & $r q \Lambda / r r$ & آزمون & \multirow{3}{*}{ كروههاى يرسنل بيمارستان با رضايت شغلى } \\
\hline & & $19 r / 01 T$ & $F \mid D \cdot / K G$ & اثر اصلى گروهها & \\
\hline & & & $\mid r / \Delta V$ & خطاى باقيمانده & \\
\hline
\end{tabular}

جدول هـ - آزمون تعقيبى بنفرونى در تشريح تفاوت معنى دار بين رضايت شغلى در كروهها

\begin{tabular}{|c|c|c|c|c|}
\hline معنى دارى & تفاوت ميانغين & \multicolumn{2}{|c|}{ مقايسه سطوح متغير گروه } & عامل \\
\hline$\cdot / K F$ & . & ادارى & درمانى & \\
\hline$\cdot 1 \cdot \cdot 1$ & $\cdot / M F$ & خدماتى & ادارى & رضايت شغلى \\
\hline$\cdot 1 \cdot \cdots$ & $\cdot / r V$ & درمانى & خدماتى & \\
\hline
\end{tabular}

در داخل بيمارستانها و محيطهاى كارى مىباشد كه تا اندازه زيادى انخيزش و رضايت شغلى افراد را تحت تأثير قرار مى دهد. يافته ديخر اين تحقيق عبارت از مطالعه تأثير حذارى متغيرهاى انغيزشى - بهداشتى هرزبرگ بر متغير رضايت شغلى بود. بر طبق اين يافتهها در ميان عوامل انخيزشى، احساس مسئوليت در كار، رشد و ييشرفت در كار و در ميان عوامل بهداشتى حقوق و دستمزد كافى و داشتن روابط دوستانه با زيردستان، همرديفان و سريرستان،

در اولويت اول و دوم براى هر دو متغير قرار داشتند (YV). براى تمامى سازمانها در هر موقعيتى مى خواهند كه مؤثر باشند حتى در موقعيتهايى كه امروزه به شدت رقابتى شدهاند، عوامل انسانى يكى از مهمرترين عوامل، سهم مهمى در اين زمينه ايفا مى كند (YN). بيمارستان ها به عنوان سازمانهايى كه براى توجه به آلام انسانها، درمان رنج و درد آنها و ارتقاى سلامت عمومى جامعه ايجاد شدهاند، بايد به رفاه كسانى كه آن را اداره مى كنند

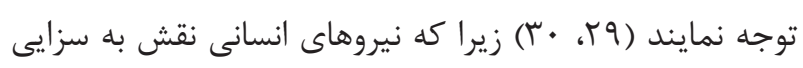
در تحول و ييشرفت امور مراقبت و درمانى دارد (اب). محققين معتقدند كه افزايش رضايت شغلى مىتواند به ارتقاى كيفيت

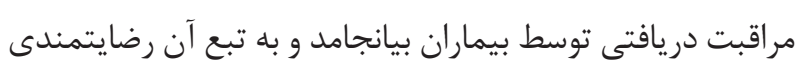

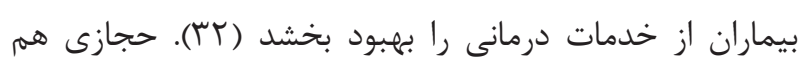

بين گروه ادارى با خدمات و نيز گروه درمانى با خدمات تفاوت معنى دارى مشاهده شد (ه • (P> (P).

\section{بحث و نتيجه كيرى}

يزوهش حاضر با هدف بررسى ميزان انخيزش و رضايت شغلى كاركنان بيمارستانهاى سنندج انجام شد. يافتههاى حاصل از اين يزوهش نشان داد كه ميزان رضايتمندى در بين سه گروه ياد شده مطلوب نمىباشد؛ به عبارت ديخر، هيج يك از گروههاى مورد مطالعه (شاغلين در بخشهاى درمانى، ادارى و خدماتى بيمارستان) سطح مطلوبى از رضايت مندى رانشان نداند. اين يافته با مطالعات ديخرى نيز همسو بود از جمله با ٍزروهش هاى انجام شده توسط صفوى و همكاران، شهبازى و سليمى و رئيسى و محبى فر، (Tr، ه ז، צY). ولى در مطالعاتى ديخر فروزانفر و همكاران نشان

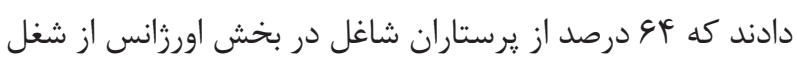
خود راضى بودند. نتايج به دست آمده را مىتوان ناشى از موقعيت و شرايط مكانى افراد و نيز نيازهاى ويزه و در حال تغيير آنان دانست؛ اينكه ارائه خدمات در يك مكان با مكان ديكر فارغ از نوع، خدمات مشابه ار ائه شده مى تواند در رضايت شغلى و انخيزش انجام آن كار متفاوت باشد و نكته ديخر وجود سازمانهاى غيررسمى ماتى 
كارى ارتباط معنى دارى نشان داد (II). حسن آبادى نيز نشان

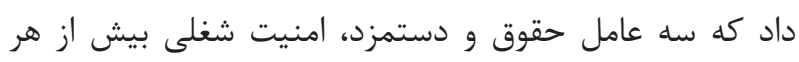

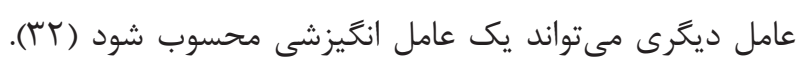

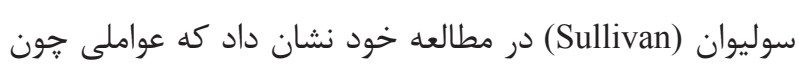

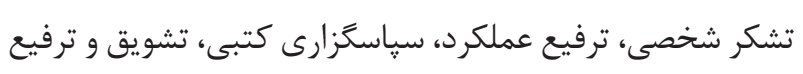

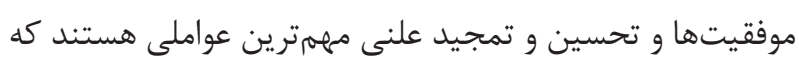

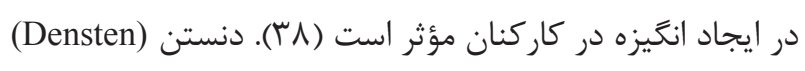

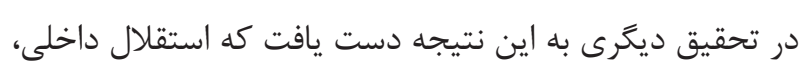

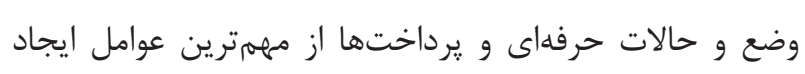
رضايت و بهبود عملكرد كار كنان هستند. بر اساس يافتههاى اين ورات مطالعه، وضعيت عوامل انخَيزشى و بهداشتى در محيط كار كاركنان

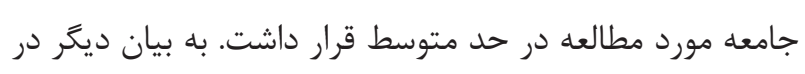

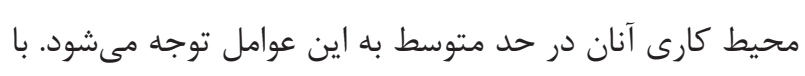

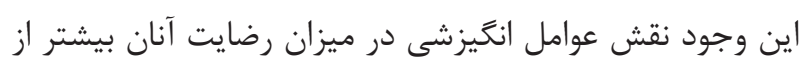

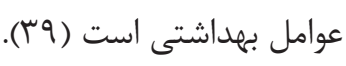
سازمانهاى بهداشتى و درمانى به علت اهميت، وظيفهاى كه در بران

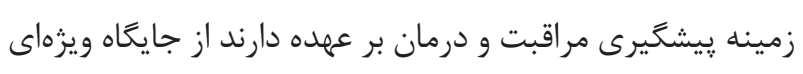
در جامعه برخوردار مىباشند و نارضايتى شغلى كاركنان مراكز درمانى موجب بايين آمدن كيفيت خدمات ارائه شده و در نهايت نارضايتى بيماران خواهد شد و توجه به نظرات و خواسته دهاى دئ آنان

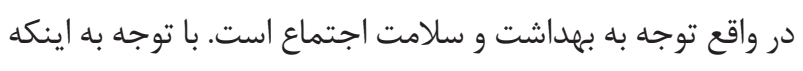

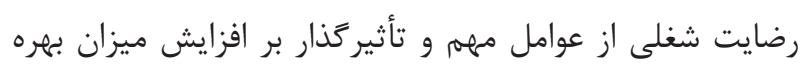
ورى سازمانها است لزوم توجه جدى به اين امر بايد در دستور

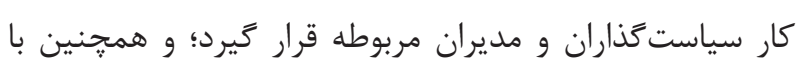

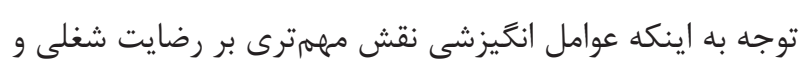

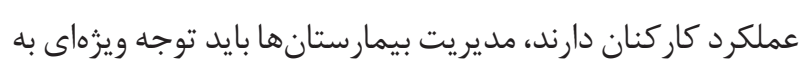

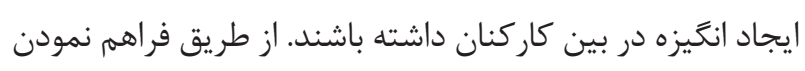

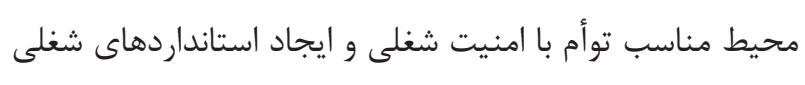
مناسب، جهت آرامش خاطر براى كاركنان مىتوان آنان را براى

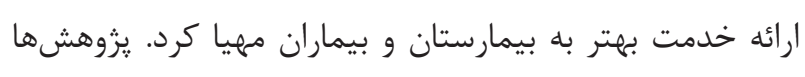
با محدوديتهاى متنوعى روبرو هستند و مطالعه حاضر نيز از

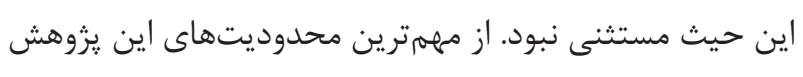

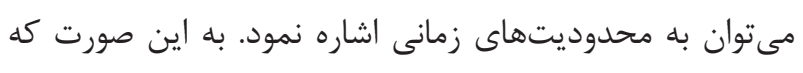

به اين نتيجه رسيد كه سه عامل ماهيت كار، امنيت شغلى و حقوق و دستمزد از عوامل بسيار مههم در ايجاد انگَيزه از ديدگاه

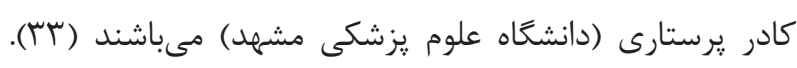

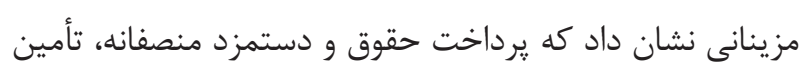

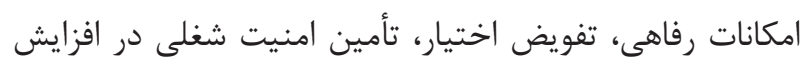

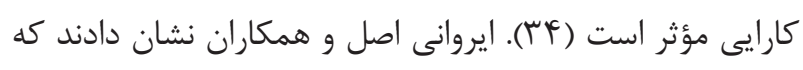

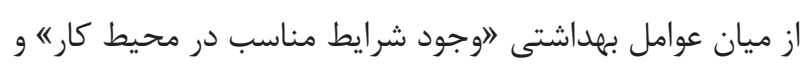

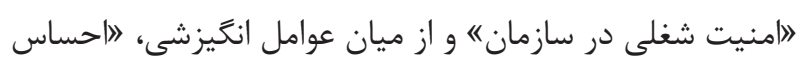

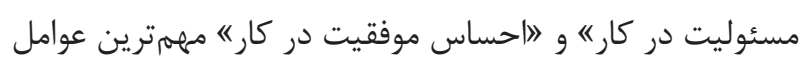

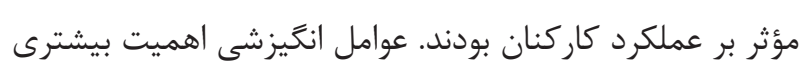

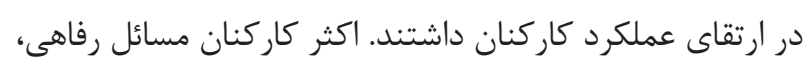
بع عدالتى، عدم شايستخى و صلاحيت مديران، عدم رضايت از

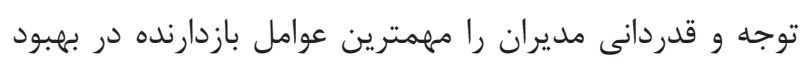

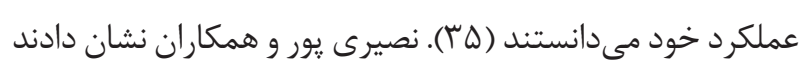
كه عوامل امنيت شغلى، حقوق و دستمزد مناسب، در زمره عوامل بهداشتى و عوامل احساس مسئوليت در كار و مورد علاقه بودن كار، در زمره عوامل انخيزشى به ترتيب در اولويت تأثير خذارترين

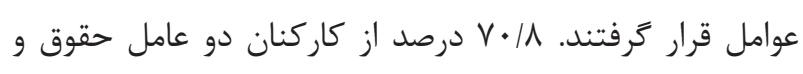

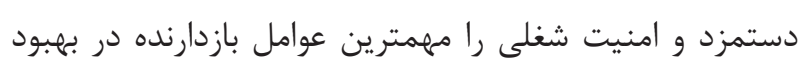

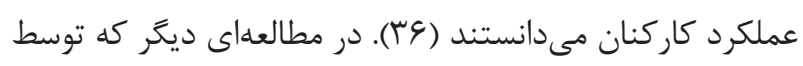
بخشى على آباد، نوروزى و حسينى انجام شد، عامل حقوق و

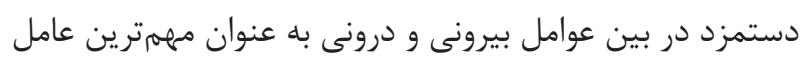

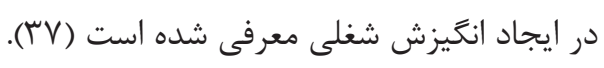

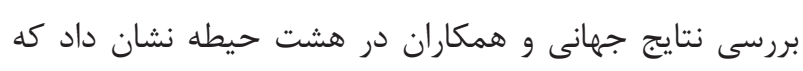

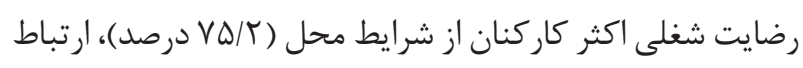

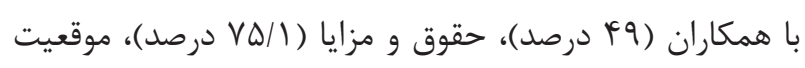

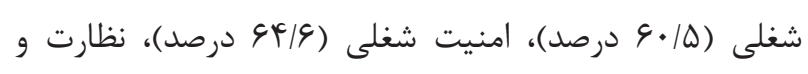

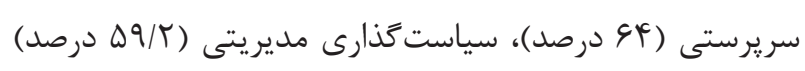

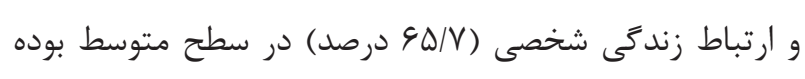

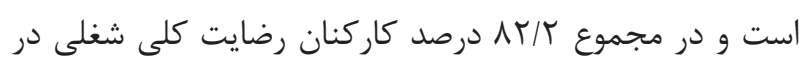

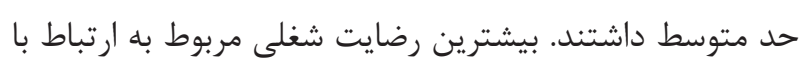
همكاران و كمترين رضايت از مزاياى سختى كار، برقرارى عدل

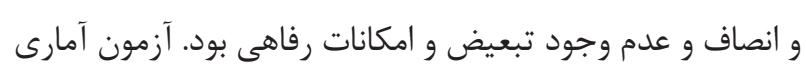
مجذور كاى بين جنس، تحصيلات، نوع استخدام، شغل و شيفت وند 
به همين دليل بررسى بعضى از مؤلفههاى روان شناختى ديخرى

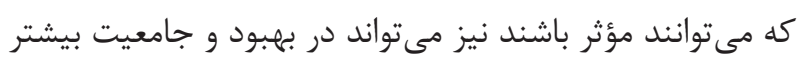

$$
\text { نتايج كارآمد باشد. }
$$

$$
\text { تشكر و قدردانى }
$$

نويسندًان اين يزوهش بر خود لازم مىدانند كه از زحمات و همكارى صميمانه كليه افراد شركت كننده تشكر و قدردانى نمايند.

\section{تعارض منافع}

هيج گَونه تعارض منافعى از سوى نويسند

\section{References}

1- Nehrir B, Ebadi A, Tofighi S, Karimi Zarchi A, Honarvar H. Relationship of job satisfaction and organizational commitment in hospital nurses. J Military Med. 2010;12(1):23-6.

2- Eghtedari A. Organization and management: systems and organizational behavior. 6th ed. Tehran: Molavi; 1995.

3- Mousavi S, Movahedi Rad S. The study of job satisfaction among nurses in Tehran military hospitals in 2014. Journal of Physician and nurse in War. 2015;2(5):183-8.

4- Nazari M. The effective factors on human resource productivity. Tehran: Islamic Azad University; 2009.

5- Thompson CA, Prottas DJ. Relationships among organizational family support, job autonomy, perceived control, and employee well-being. J Occup Health Psychol. 2006;11(1):100-18. DOI: 10.1037/1076-8998.10.4.100 PMID: 16551178

6- Seif A. Educational psychology. Tehran: Agah publication; 2007.

7- Seyedjavadin R. Human resourses management and staff affairs. Tehran: Neghahe-Danesh; 2013.

8- Saatchi M. Aplicational psychology for managers in home, school and organization. 1st ed. Tehran: Virayesh; 1995.

9- Ma CC, Samuels ME, Alexander JW. Factors that influence nurses' job satisfaction. J Nurs Adm. 2003;33(5):293-9. DOI: 10.1097/00005110-200305000-00005 PMID: 12792284

10- Rosta J, Nylenna M, Aasland OG. Job satisfaction among hospital doctors in Norway and Germany. A comparative study on national samples. Scand J Public Health. 2009;37(5):503-8. DOI: 10.1177/1403494809106504 PMID: 19535404

11- Koelbel PW, Fuller SG, Misener TR. Job Satisfaction of Nurse Practitioners. The Nurse Practitioner. 1991;16(4). DOI: 10.1097/00006205-199104000-00007

12- Mirsepasi N. Strategic human resource management and labor relations. 7th ed. Tehran: Mir; 2010.

13- Shoghi B, Zamani Moghadam A, Jafari P. The effect of organizational wisdom on Job satisfaction with due attention
عمقى افراد نمونه مى توان اطلاعات موثق بيشترى به دست آورد.

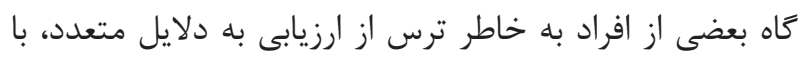

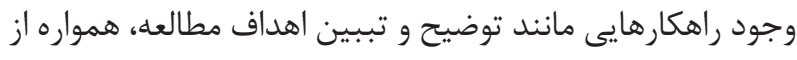

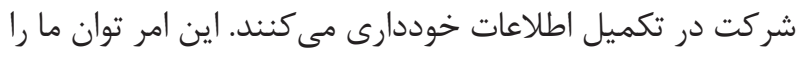
براى تكميل نمونه كاهش مى داد. علاوه بر اين بررسى متغيرهاى روان شناختى ديكر مىتواند اطلاعات مناسبى در برداشته باشد. بدون شك وضعيتهاى روان شناختى (جه به صورت حالت و و يا

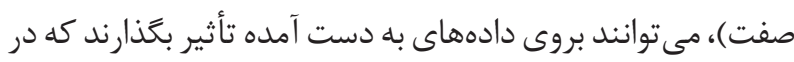

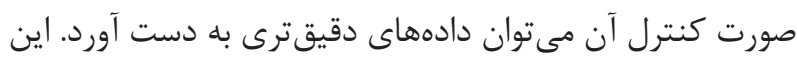

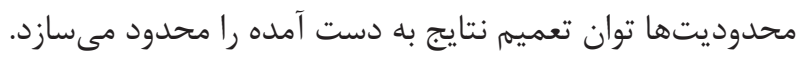

to the Mediation role of emotional intelligence. Productivity Management. 2018;11(43):75-106.

14- Hersey P, Blanchard K. Management of Organizational Behavior (HR application). Tehran: Kabir; 2010.

15- Naeli M. Motivation in organizations. Ahwaz: Chamran University; 2010.

16- Hosseininejad S, Aminiahidashti H, Montazer S, Elyasi F, Moosazadeh M, Ahmadi N. Job Burnout among the Emergency Department Nurses of Medical Training Centers Affiliated to Mazandaran University of Medical Sciences. Iranian J Emergency Med. 2016;3(4):125-31.

17- Gholami Fesharaki M, Akbari H, Akbari H, Mohammadian M. Nurse Job Satisfaction Compare with Healthcare Personnel: A Cause Cross Sectional Study. Health Research Journal. 2016;1(1):1-2. DOI: 10.20286/hrj-010125

18- Easom A. Nephrology APNs: who are we and what do we do? Nephrol Nurs J. 2009;27(2):187-91.

19- Amozadeh H, Razavi H. Herzberg's two-factor theory, valid or Atbar. MJLH Policy. 2008:29-32.

20- Kohestani H, Baghchechi N, Abed Saeedi J, Chezelbash A. Determiningthe association between low back pain and occupational stress in nurses. Journal of Arak University of Medical Sciences (Rahavard-e-Danesh). 2006;9(3):73-81.

21- Jahani F, Farazi A, Rafie M, Jadidi R, Anbari Z. Job satisfaction and its related factors in Arak staff. Journal of Gorgan University of Medical Sciences. 2009;13(1).

22- Waltz C, Bausell R. Nursing Research: Design, Statistics, and Computer Analysis. Philadelphia: W.B. Saunders Co; 1981.

23- Raeisi P, Mohebbifar R. Job motivators from the employees and managers' point of view in teaching hospitals affiliated to Qazvin University of Medical Sciences. The Journal of Gazvin University of Medical Sciences. 2008;10(1):101-8.

24- Schiestel C. Job satisfaction among Arizona adult nurse 
practitioners. J Am Acad Nurse Pract. 2007;19(1):30-4. DOI: 10.1111/j.1745-7599.2006.00187.x PMID: 17214865

25- Shahbazi L, Salimi T. Job satisfaction of nurses employed in hospitals. Journal of Shaeed Sdoughi University of Medical Sciences Yazd. 2012;10(3):70-3.

26- Safavi M, Abdollahi SM, Salmani Mood M, Rahimh H, Nasirizade M. Relationship between nurses' quality performance and their job satisfaction. Quarterly J Nersing Manage. 2017;6(1):53-61. DOI: 10.29252/ijnv.6.1.53

27- Zanfar Mehdi M, litaleshi H, Hashemi B, Baratloo A, Motamedi M, Majidi A, et al. Emergency Nurses Job satisfaction and its determinants in the Hospitals of Shahid Beheshti university of medical scinces. Advances in Nursing \& Midwifery. 2013;23(80):10-23.

28- Forughi F, Kharrazi H, Iranfar S, Rezaei M. Job satisfaction and its affecting factors from the viewpoints of faculty members of Kermanshah University of Medical Sciences. Iranian Journal of Medical Education 2008;7(2):335-42.

29- Hazavehei M, Samadi A. Factors Contributing in Job Satisfaction in Employees of Hamedan Governmental Organizations. J Research in Behavioural Sciences. 2007;5(1):47-53.

30- Goyal R. Human Resource Management in Hospitals. New York: Prentice Hall India Pvt; 2000.

31- Mahmoudi H, Ebrahimian A, Solymani M, Ebadi A, Hafezi S, Fayzi F. The Study of Job Motivation Factors in Critical Care Nurses. Journal of Behavioral Sciences. 2007;1(2):171-8.

32- Hassan Abadi A. Factors which are affected on human forces motivation who work in Iran water and power resources development company based on Herzberg theory [Dissertation]. Tehran: Institute for Management and Planning Studies; 2000.

33- Hejazi A. Evaluation of nurses comments regarding the factors of occupational motivations in the hospitals related to Mashhad medical University [Dissertation]. Tehran: Science and Research Campus Azad University; 1997.

34- Mazinani M. Motivation and increased efficacy of Takab Nirou company Personnel [Dissertation]. Tehran: Faculty of Economic and Business, Tehran University; 1996

35- Irvan M, Behbahani A, Nosratinejad F, Gholamrezanejad A. The relationship between job satisfaction and Hertzberg's motivative - hygienic factors in staffs of Yasouj hospitals. Medical Sciences. 2010;20(1):45-51.

36- Nasiripour AA, Delgoshaie B, Kalhor R, Kiaei MZ, Shahbahrami E, Tabatabaee SS. Effective Factors On Staffs' Job Satisfaction Based On Herzberg Theory In Qazvin Teaching Hospitals. Payavard. 2013;7(4):354-65.

37- Bakhshi Ali Abadi H, Norouzi D, Hosseini ZS. Effective Factors on Job Motivation in Academic Members of Rafsanjan Medical University. Iranian Journal of Medical Education. 2004;4(2):3341.

38- Sullivan P. Office Morale.

39- Densten IL. Clarifying inspirational motivation and its relationship to extra effort. Leadership \& Organization Development Journal. 2002;23(1):40-4. DOI: 10.1108/01437730210414553 